\title{
Simple Assessment of Spatio-Temporal Evolution of Salt Marshes Ecological Services
}

\section{A. Rita Carrasco* \\ Centro de Investigação Marinha e Ambiental, Universidade do Algarve, Faro, Portugal}

A number of previous research studies have addressed the enormous role played by biodiversity and ecosystems in human well-being and have placed particular emphasis on the consequences of the reduction or loss of these services. A handful of studies have implemented practical methodologies to quantify the variability of limiting factors leading to reductions in these ecological services. The aim of this article is to document the limited number of studies that have analyzed coastal ecosystem services and acknowledge the impacts of physical changes in habitat provision. In one example, it is clear that the maintenance of salt marshes depends on sedimentary supply and consequent morphological variability in spite of the fact that there is usually no recurrent integration of habitat time-space dynamics (sediment availability) during the quantification and monetization of marsh services (i.e., monetary valuation of salt marsh services). This means that one key challenge facing the analysis of salt marsh (or other ecosystem) services in a global climate context is to predict future value, based on past trends, while at the same time guaranteeing conservation. Research in this field has been very broad and so the use of long-term evolutionary datasets is proposed here to explain future habitat provision. An empirical approximation is also presented here that accounts for service provision and enables time-space analysis. Although improvements will be required, the equation presented here represents a key first step to enable managers to cope with the constraints of resource limitations and is also applicable to other habitats.

Keywords: ecosystem services, time, physical changes, conservation, salt marsh

\section{INTRODUCTION}

Coastal and terrestrial ecosystems all provide a number of fundamental life-supporting services (i.e., natural capital, namely varied benefits that humans freely gain from the nature; Costanza et al., 2017) and societal goods (i.e., that benefits the largest number of people in the largest possible way; Daily, 1997; Costanza et al., 2017) on which human welfare is dependent (Millennium Ecosystem Assessment, 2005; Carpenter et al., 2006). de Groot et al. (2002) explains the assessment of ecosystem goods and services has involving the translation of the ecological complexity (structures and processes) into a number of ecosystem functions (i.e., the capacity of natural processes and components to provide goods and ecosystem services) that satisfy human needs, directly or indirectly (in agreement with Daily, 1997; Balmford et al., 2002).

Significant research has therefore been devoted to explaining declines in services and the survival rates of coastal ecosystems over the last two decades. A brief history of ecosystem services and natural capital can be found in Costanza et al. (2017). In previous research, 
Costanza et al. (1997) and others have presented interesting perspectives about how the world economy would come to an abrupt stop if such ecosystems and their services were to cease to exist (e.g., Turner et al., 2003; Palmer et al., 2005; Carpenter et al., 2006). Ecosystem services can be particularly important at a national and sub-national scale, if they play an effective role in making informed decisions about the use and management of the planet's resources, especially when trade-offs and synergies need to be taken into account (Balvanera et al., 2017). However, although recent scientific efforts have focused on quantifying current ecosystem service provisions in detail (e.g., Barbier et al., 2011; de Groot et al., 2012; Costanza et al., 2014), much less attention has been paid to the evolution of these variables in time and space, especially in light of future climatic adjustments (Greenberg et al., 2006). This lack of information can be filled with an increase in the number of conservation studies advising that ecosystem service provisions are limited in time, and they should be predicted based on prediction of spatial changes (Koch et al., 2009). Moreover, natural processes are characterized by thresholds and limiting functions (Koch et al., 2009), and ecosystem provision may sometimes not occur linearly.

The representation of the temporal dynamics of ecosystem services is a crucial research frontier in the field of ES modeling (e.g., Rova et al., 2019). Thus, it is clear that enhanced research on the spatio-temporal dynamics of ecosystems is likely to contribute to reductions in the cost of coastal conservation actions given the ongoing effects of climate change. A time-spaceevolutionary analysis therefore purports to past information about physical changes through time (e.g., via morphology, morphodynamics, or morphometric analysis) within a given coastal ecosystem and can therefore help to predict the temporal functionality of such a system (scenarios).

The aim of this perspective is to express concerns about the need for a more compelling and integrative approach that triggers the analysis of variation in temporal (and spatial) coastal ecosystem services. A reminder is presented here that ecosystem service provision analysis should couple both current ecological state (i.e., flow or actual ecosystem service use) with morphological variability in order to enable more effective and sustainable ecosystem management. The morphological variability of a given ecosystem determines stock, or the potential provision of ecosystem services. Salt marshes are very commonly cited examples in ecosystem research, and so these habitats (i.e., natural environment supporting functional and structural functions) are discussed here in an attempt to express the degree of relationship between the various factors affecting given system variability as well as their expected impact on the services provided.

\section{FREQUENT USE OF THE TERM "MORPHOLOGICAL VARIABILITY" IN COASTAL ECOSYSTEM SERVICES ARTICLES}

The Thomson Reuters Web of ScienceTM database (WoS; web of science core collection) was mined in this analysis to compile articles in English purporting to relate coastal ecosystem services with morphological variability. This approach enabled an understanding of just how detached the two processes remain from one another in the recent scientific literature. The scientific terms used in each search have a cross-disciplinary relationship between them. This allows us to understand the evolution of a topic in a scientific domain; thus, strings and terms were defined on an author-byauthor basis after reviewing articles about ecosystem services and the most relevant keywords. Papers were automatically identified by searching the terms throughout the published text. All output results were generated by WoS and utilized the same result exploitation search strategy as used in other studies (e.g., Chang et al., 2017; Walls, 2018; Wang et al., 2018; Zhao et al., 2018).

The Boolean search operators "ecosystem services" and "coast" were used for the first level of search in January, 2019 (Indexes=SCI-EXPANDED, SSCI, A\&HCI, CPCI-S, CPCISSH, ESCI, CCR-EXPANDED, IC Timespan=All years); this approach led to the identification of 1,920 English articles from 108 different countries around the world published over the last 20 years to acknowledge coastal ecosystem services. This first level of search allowed the establishment of a starting sample universe and also limited the output of ecosystem services in relation to coastal domain context. The articles output from this search were distributed within five main WoS categories encompassing environmental sciences and ecology, marine and freshwater biology, oceanography, water resources, science technology, and other topics (Figure 1). Each of these subject categories contained at least $10 \%$ of the total number of search records; those referring to coastal ecosystem services (including the terms "ecosystem services" and "coast") can be shown to decrease in number from environmental and biological sciences into their physical counterparts, including oceanography and other topics with less outputs (Figure 1). This result suggests that most research to date has been concentrated within ecology and on conservation issues.

The second level of search undertaken here was aimed at validating the dependence between coastal ecosystem services studies and morphological variability. Thus, the terms "ecosystem services," "coast," and "morphology" (including "morphodynamics" or "morphometric") where searched in this case but led to the identification of just 35 published articles to acknowledge the morphological variability of coastal ecosystem services, albeit in increasing numbers over the last 4 years. As this comprises just $2 \%$ of total records output across the broad field of coastal ecosystem services (i.e., from a total of 1,920), it is clear that morphological variability analysis has not often been included in ecosystem services articles. A coupling between coastal ecosystem services and morphological variability is most frequent in marine biological and oceanography research categories (Figure 1).

The terms used in the first and second levels of search were defined based on the key concepts of the discussion herein presented, the topic- "ecosystem services," the domain- "coast," 


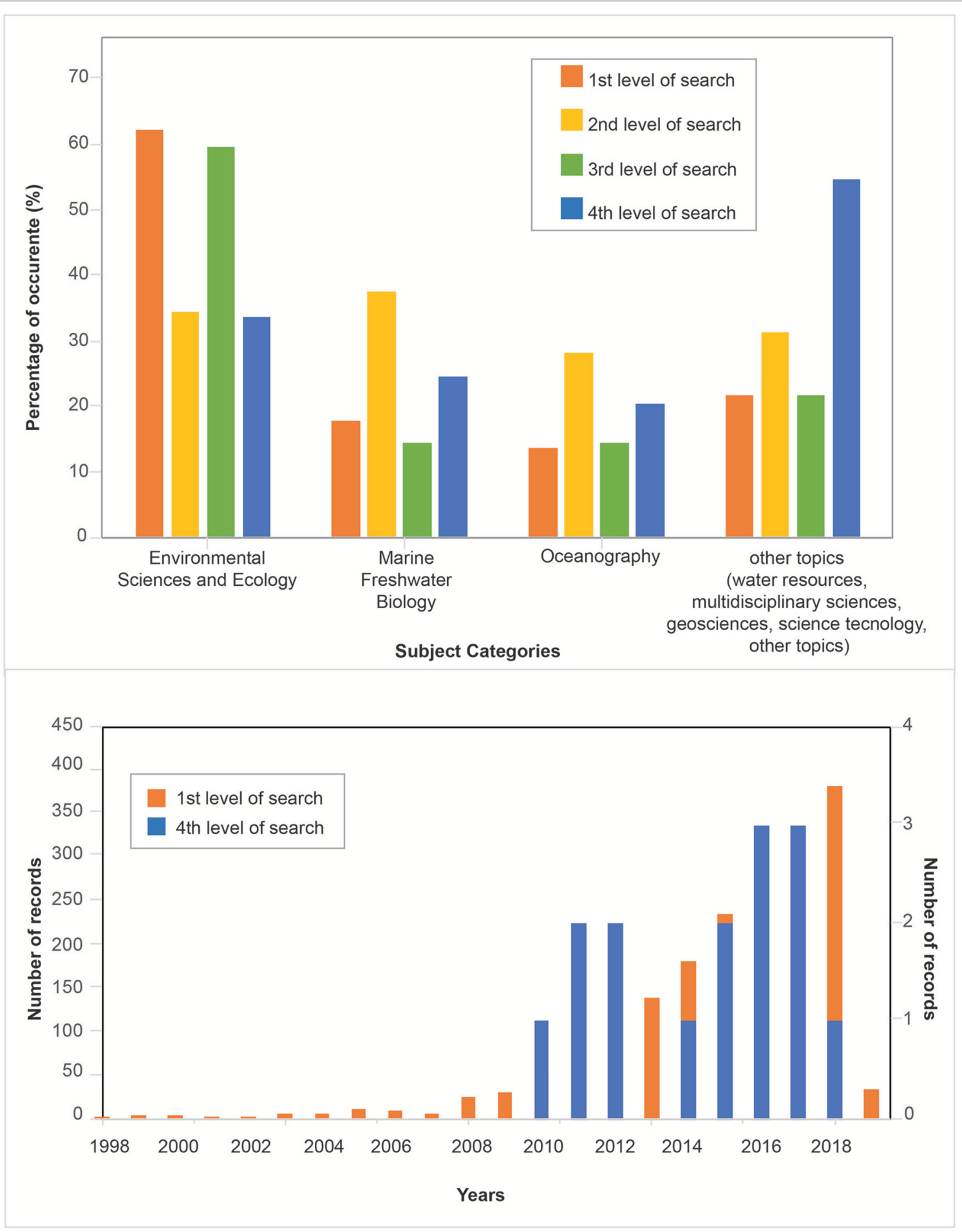

FIGURE 1 | Above, records reporting coastal ecosystem services, morphology analyses, and salt marsh strings obtained for the last 20 years, for the four levels of search, distributed within the five main WoS categories; below, comparison between the number of records obtained for the last 20 years in the first level of search and in the fourth level of search.

and the analysis-"morphology." There was no manipulation of the generated output results and, as initially preconized, they express the content of all publications in natural sciences, conducted in the last decades. The majority of authors of the different works used the same terms to express different conclusions on the same topic and/or domain. 


\section{FREQUENT USE OF THE TERM "MORPHOLOGICAL VARIABILITY" IN SALT MARSH ECOSYSTEM SERVICES ARTICLES}

The WoSwas then searched at a third level to compile studies relating coastal ecosystem services and the morphological variability of salt marshes. With the introduction of the third level of search, it is possible to limit output results to a specific subject. The terms "ecosystem services," "coast," and "salt marsh (or saltmarsh)" were considered here and led to the identification of 247 articles that acknowledge the ecological value of salt marsh systems, mostly in environmental and biological sciences, and oceanography (Figure 1). The fourth search level also considered the terms "ecosystem services," "coast," "salt marsh" (or "saltmarsh"), and "morphology" (including "morphodynamics" and "morphometric") but led to the identification of just 15 articles (i.e., $37 \%$ of 247 acknowledging "salt marsh ecosystems") establishing a connection between salt marsh evolution and morphological variability (Figure 1). As the records output from this fourth level search are distributed between biological and physical categories, a recognition of the importance of morphological variability on salt marsh services assessment was also performed, but only for the last 10 years (Figure 1). Therefore, questions remain regarding whether current assessments of salt marsh ecosystem provision are incomplete and regarding how morphological variability, a factor not included very often in salt marsh (ecosystem) services, should be studied.

\section{PHYSICAL PROCESSES LEADING TO CHANGES IN SALT MARSHES}

Salt marshes are one of the most productive ecosystems on Earth (e.g., Caçador et al., 2015). Thus, if these ecosystems are left to migrate and adapt unimpeded (Kirwan et al., 2016b), such marshes may lessen the adverse impacts associated with sea level rises, including increases in coastal flooding, storm surges, and erosion (Bouma et al., 2014). Salt marshes also act like sponges, absorbing excess water, and reducing flooding, but persist as a delicate balance between their own growth and changing sea levels (Schile et al., 2014). Projecting future changes in salt marshes is a crucial step toward planning for and mitigating the impact of climate change on marsh biodiversity, as well as for detect early warning tipping points in these complex systems (Crosby et al., 2016).

Marsh coastal areas have been squeezed due to sea level rises and erosion, both primary threats to these ecosystems around the world (Torio and Chmura, 2013). Although sea level rise can pose a serious threat to the survival of salt marshes, there is growing evidence that as long as sediment supply is sufficient, vegetationsedimentation feedback enables these ecosystems to vertically accrete in concert with sea level change (e.g., Redfield, 1972; Kirwan and Temmerman, 2009; IPCC, 2013; Carrasco et al., 2016; Kirwan et al., 2016a).
Sea level rise has been portrayed as creating accommodation space within which fine-grained sediments can settle (sediment supply rate); this increases in concert with the rate of sea level rise and theoretically can lead to concomitant changes in mineral sediment deposition (Carrasco et al., 2016); given high rates of sea level rise, however, alongside an insufficient supply of sediment and organic material, salt marsh inundation is likely to occur. In contrast, if the rate of sediment supply is much higher than that of sea level rise, silting-up will dominate, a marsh will shift toward a different environment and ecosystem, and areal losses should be expected (e.g., Schile et al., 2014; Carrasco et al., 2016). The overall morphological stability of salt marsh ecosystems in response to rising sea level depends on the present elevation of the marsh community in relation to its depth-response curve and the local mean sea level (e.g., Morris et al., 2002).

All of these outcomes suggest that the future of salt marshes and their services should be founded on an understanding of temporal and spatial morphological variability as well as via the identification of different target states. Although recent scientific efforts have been focused on quantifying salt marsh ecosystem provisions (Chmura, 2012; de Groot et al., 2012; Ouyang and Lee, 2014) as well as in determining the effect of sediment supply on the growth of marshes (e.g., Lovelock et al., 2011; Rizzetto and Tosi, 2012; Kirwan et al., 2016b; Müller-Navarra et al., 2019), the two approaches remained detached and so less attention has been paid to spatio-temporal service dynamics and will require adjustments. The result of this analysis therefore advances the conclusion that the maintenance of ecosystem services and the assessment of future salt marsh services provision in a global climate change context (as well as in other coastal ecosystems) should be based in the analysis of long-term physical datasets (e.g., Barbier et al., 2008). As it is essential that natural variability and cumulative effects be considered in the valuation of ecosystem services (Koch et al., 2009).

A number of previous studies, although not exclusively investigating ecosystem services, have nevertheless demonstrated the importance of past trends in coastal decision making and planning (e.g., Baily and Nowell, 1996; Murray et al., 2014; Chang et al., 2018; Wu et al., 2018). In terms of coastal planning efficiency and effectiveness variables considered by policy-makers over recent decades, emphasis has been placed on long-term trend analyses of hydro forcing mechanisms and their spatial distribution with a view to formulating climate change and sea level rise management plans. In previous work, Santana-Cordero et al. (2016) also demonstrated the key role of historical datasets to understanding socio-ecological dynamics and ecosystem services within a Mediterranean coastal landscape, as well as for prioritizing conservation tasks and formulating governance. Although previous researchers have illustrated these variables in practical terms, any relationship must encompass time-space dynamics and the amount of service provision. Just a handful of studies have so far been able to demonstrate the impact of long-term datasets on ecosystem-based approaches (e.g., Rieb et al., 2017), or in the modeling of the dynamics of multiple services (e.g., Rova et al., 2019), and so a framework is therefore proposed here (Figure 2) for the future analysis of ecosystem services. This framework suggests that the cumulative 


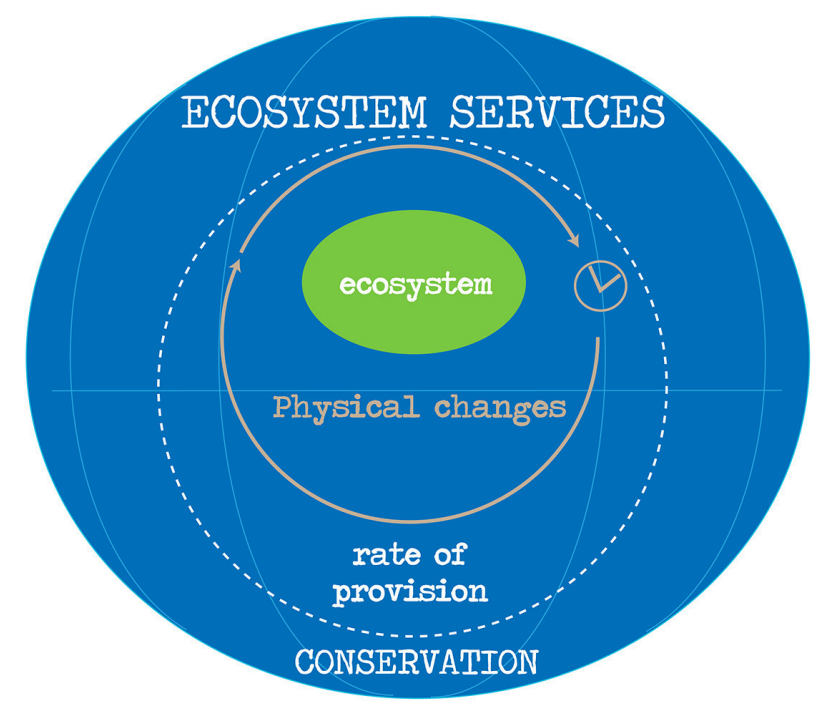

FIGURE 2 | A framework for ecosystem service analysis based on physical changes through time and space; the dashed white line in this figure limits the conservation dimension that should be taken into account alongside temporal variability in physical changes (brown line coupled with a clock symbol) for a certain ecosystem (green ellipse).

changes observed in the past (clock time in Figure 2) should be contained and serve as limitation to predictions of the provision rate; this rate encompasses an open boundary (dashed line) in the broad context of ecosystem service assessments, conservation, and the surrounding environment (Figure 2). In a first hand, the amount of physical variation in time (Figure 2) shown by a given ecosystem can be used to predict the rate of service provision; and in a second hand, the changes in time in the rates of provision can be used to schedule conservation measures distributed in time. Indeed, by including a time-space analysis (e.g., ecosystem growth or reduction tendency), it is possible to predict different scenarios for future services provision. Although modest, this is a reasonable assertion in coastal areas and in the framework of climate change. The framework proposed here is nevertheless sustainable and can be adapted via other ecosystembased approaches.

\section{IMPROVING ECOSYSTEM SERVICES CONSERVATION EFFECTIVENESS UNDER MORPHOLOGY ANALYSIS}

A detailed time-space analysis includes lifetime features (e.g., the presence or absence of environments) and volumetric tendencies and is based on ecological dynamics (e.g., vegetation types and canopy) and their relationship with human alterations. It is therefore vital to understand both past and current ecosystem behaviors in this context; examples of morphological variables that be useful in predicting changes in marsh provision include cartographic variables (i.e., spatial length and width) as well as sediment accumulation rates (e.g., at different marsh zones), amongst others.

Analytical timeframes for time-space consideration should be established according to available datasets, while at the same time bearing in mind that longer-term analyses enable more adequate predictions for future evolution. This means that, depending on existing datasets, variables can be coupled, or separately applied, to predict service provision volumes. In one example, salt marsh past horizontal evolution (e.g., shape variability) and sediment accumulation rates can usefully be integrated, marsh morphological evolution, for a given time period (dt), and then multiplied by the current provision (Pcurrent) to predict service provision, ESPmarsh, for a given future time period (time = i; Equation 1), as follows:

$$
\text { ESPmarsh }(i)=\text { Pcurrent } \int_{t 0}^{t} f(\operatorname{marsh}) d t
$$

Thus, over a 100 year time period from present $(\mathrm{I}=100)$, the marsh provision of a certain service ESPmarsh (100) can be determined by multiplying current provision, Pcurrent, with the rate of morphological change over recent years $[\mathrm{f}($ marsh $)]$. The latter incorporates both time and space dimensions, i.e., as erosion, accretion, growth, reduction, increase, decrease, amongst others. ESPmarsh is thus a predictor of evolution that accounts for the ecosystem cumulative changes over time.

Equation (1) can be individually applied for each service as Pcurrent (and the rate of morphological change over recent years) is dependent on the type of positive service provided. The total value of each offered service (i.e., Provision services, Regulation services, Habitat services, and Cultural services; Costanza et al., 1997) per habitat in monetary units (de Groot et al., 2012) can also be subsequently determined. Thus, Equation (1) also enables different provision rates for services to be distinguished as well as across analytical periods. This approach also enables a timeprovision curve to be completed for a given habitat, and assists coastal stewards to more accurately put habitat conservation in place. This also leads to enhanced plasticity during the construction and discussion of morphological change scenarios. The equation is of a simple application by a non-expert public (e.g., coastal decision making). The multifactorial interaction (or non-linearities in ecosystem) could be part of an improved formula version, but it would depend very much on the type of the ecosystem, besides having direct site-specific limitations.

\section{SUMMARY}

Although the dependence between ecology and geophysics for coastal and marine sciences has been well-described in the literature, the same relationship needs to be better described within the context of ecosystem services analysis. Significant research over the past two decades has therefore been devoted to explaining the importance of coastal ecosystem services, but just a few have described the available methodologies to access the factors limiting and affecting its evolution.

This work advances that the future maintenance of coastal ecosystem services, including increases and decreases in service 
provision, necessitates the study of time-space variability. A strong connection between the amount of services provided and the habitat morphological changes was underlined. This should be valid for other coastal systems, salt marsh being an example.

It is concluded that long-term spatial analyses should become one of the most important prerequisites when predicting the amount of services provided. The benefits of longterm predictions in the provision of services will enable the maximization of effective conservation, value maintenance and optimized opportunities vs. minimized risk, in the event that services are lost.

\section{DATA AVAILABILITY}

All datasets generated for this study are included in the manuscript and/or the supplementary files.

\section{REFERENCES}

Baily, B., and Nowell, D. (1996). Techniques for monitoring coastal change: a review and case study. Ocean Coast. Manage. 32, 85-95. doi: 10.1016/S0964-5691(96)00058-0

Balmford, A., Bruner, A., Cooper, P., Costanza, R., Farber, S., and Green, R. E. (2002). Economic reasons for conserving wild nature. Science 297, 950-953. doi: 10.1126/science.1073947

Balvanera, P., Quijas, S., Karp, D. S., Ash, N., Bennett, E. M., Boumans, R., et al. (2017). "Ecosystem Services," in The GEO Handbook on Biodiversity Observation Networks, eds. M. Walters and R. J. Scholes (Cham: SpringerOpen) 39-78. doi: 10.1007/978-3-319-27288-7_3

Barbier, E. B., Hacker, S. D., Kennedy, C., Koch, E. W., Stier, A. C., and Silliman, B. R. (2011). The Value of estuarine and coastal ecosystem services. Ecol. Monogr. 81, 169-183. doi: 10.1890/10-1510.1

Barbier, E. B., Koch, E. W., Silliman, B., Hacker, S. D., Wolansk, E., Primavera, J., et al. (2008). Coastal ecosystem-based management with non-linear ecological functions and values. Science 319, 321-323. doi: 10.1126/science. 1150349

Bouma, T. J., van Belzen, J., Balke, T., Zhu, Z., Airoldi, L., Blight, A. J., et al. (2014). Identifying knowledge gaps hampering application of intertidal habitats in coastal protection: opportunities \& steps to take. Coast. Eng. 87, 147-157. doi: 10.1016/j.coastaleng.2013.11.014

Caçador, I., Duarte, B., Marques, J. C., and Sleimi, N. (2015). “Carbon mitigation: a salt marsh ecosystem service in times of change," in Halophytes for Food Security in Dry Lands, eds M. A. Khan, M. Ozturk, B. Gul and M. Z. Ahmed (Elsevier), 83-110. doi: 10.1016/B978-0-12-801854-5.00006-6

Carpenter, S. R., Bennett, E. M., and Peterson, G. D. (2006). Scenarios for ecosystem services: an overview. Ecol. Soc. 11:29. doi: 10.5751/ES-01610-110129

Carrasco, A. R., Ferreira, Ó., and Roelvink, D. (2016). Coastal lagoons and rising sea level: a review. Earth-Sci. Rev. 154, 356-368. doi: 10.1016/j.earscirev.2015.11.007

Chang, H. T., Lin, M. H., Hwang, I. H., Chen, T. J., Lin, H. C., Hou, M. C., et al. (2017). Scientific publications in gastroenterology and hepatology in Taiwan: an analysis of web of science from 1993 to 2013. J. Chin. Med. Assoc. 80, 80-85. doi: $10.1016 /$ j.jcma.2016.06.006

Chang, Y., Chu, K., and Chuang, L. K. (2018). Sustainable coastal zone planning based on historical coastline changes: a model from case study in Tainan, Taiwan. Landsc.Urban Plan. 174, 24-32. doi: 10.1016/j.landurbplan.2018.02.012

Chmura, G. L. (2012). What do we need to assess the sustainability of the tidal salt marsh carbon sink? Ocean Coast. Manage. 83, 25-31. doi: 10.1016/j.ocecoaman.2011.09.006

\section{AUTHOR CONTRIBUTIONS}

The author confirms being the sole contributor of this work and has approved it for publication.

\section{FUNDING}

AC was supported by a contract under the scope of the D.L. n. ${ }^{\circ}$ $57 / 2016$, changed by Law $n^{\circ} 57 / 2017$. This is a contribution to the EVREST project (PTDC/MAR-EST/1031/2014), funded by national funds from Fundação para a Ciência e Tecnologia, IP.

\section{ACKNOWLEDGMENTS}

The author acknowledges the reviewers for the helpful comments and suggestions.

Costanza, R., D’Arge, R., de Groot, R. L., Farberk, S., Grasso, M., Hannon, B., et al. (1997). The value of the world's ecosystem services and natural capital. Nature 397, 253-260.

Costanza, R., de Groot, R., Braat, L., Kubisze- Wski, I., Fioramonti, L., Sutton, P., et al. (2017). Twenty years of ecosystem services: How far have we come and how far do we still need to go? Ecosyst. Serv. 28, 1-16. doi: 10.1016/j.ecoser.2017.09.008

Costanza, R., de Groot, R., Sutton, P., van der Ploeg, S., Anderson, S. J., Kubiszewski, I., et al. (2014). Changes in the global value of ecosystem services. Glob. Environ. Chang. 26, 152-158. doi: 10.1016/j.gloenvcha.2014.04.002

Crosby, S. C., Sax, D., Palmer, M. E., Booth, H. S., Deegan, L. A., Bertness, M. D., et al. (2016). Salt marsh persistence is threatened by predicted sea-level rise. Estuar. Coast. Shelf Sci. 181, 93-99. doi: 10.1016/j.ecss.2016.08.018

Daily, G. (1997). Nature's Services: Societal Dependence on Natural Ecosystems. Washington, DC: Island Press, 392.

de Groot, R., Brander, L., Ploeg, R., Costanza, R., Bernard, F., Braat, F., et al. (2012). Global Estimates of the value of ecosystems and their services in monetary units. Ecosyst. Serv. 1, 50-61. doi: 10.1016/j.ecoser.2012.07.005

de Groot, R. S., Wilson, M. A., and Boumans, R. M. J. (2002). A typology for the classification, description and valuation of ecosystem functions, goods and services. Ecol. Econ. 41, 393-408. doi: 10.1016/S0921-8009(02)00089-7

Greenberg, R., Maldonado, J. E., Droege, S., and McDonald., M.V. (2006). Tidal marshes: a global perspective on the evolution and conservation of their terrestrial vertebrates. BioScience 56, 675-685. doi: 10.1641/00063568(2006)56[675:TMAGPO]2.0.CO;2

IPCC (2013). “Climate Change 2013: The Physical Science Basis," in Contribution of Working Group I to the Fifth Assessment Report of the Intergovern- mental Panel on Climate Change, eds. T. F. Stocker, D. Qin, G. K. Plattner, M. Tignor, S. K. Allen, J. Boschung, et al. (Cambridge; New York, NY: Cambridge University Press) 1535.

Kirwan, M., and Temmerman, S. (2009). Coastal marsh response to historical and future sea level acceleration. Quatern. Sci. Rev. 28, 1801-1808. doi: 10.1016/j.quascirev.2009.02.022

Kirwan, M. L., Temmerman, S., Skeehan, E. E., Guntenspergen, G. R., and Fagherazzi, S. (2016a). Overestimation of marsh vulnerability to sea level rise. Nat. Clim. Chang. 6, 253-260. doi: 10.1038/nclimate2909

Kirwan, M. L., Walters, D. C., Reay, W. G., and Carr, J. A. (2016b). Sea level driven marsh expansion in a coupled model of marsh erosion and migration. Geophys. Res. Lett. 43, 4366-4373. doi: 10.1002/201 6GL068507

Koch, E. W., Barbier, E. B., Silliman, B. R., Reed, D. J., Perillo, G. M. E., Hacker, S. D., et al. (2009). Non-linearity in ecosystem services temporal and spatial variability in coastal protection. Front. Ecol. Environ. 7:126. doi: $10.1890 / 080126$ 
Lovelock, C., Bennion, V., Grinham, A., and Cahoon, D. (2011). The role of surface and subsurface processes in keeping pace with sea level rise in intertidal wetlands of Moreton Bay, Queensland, Australia. Ecosystems 14, 745-757. doi: 10.1007/s10021-011-9443-9

Millennium Ecosystem Assessment (2005). Ecosystems and Human Well-being: Synthesis. Washington, DC: Island Press. 138.

Morris, J. T., Sundareshwar, P. V., Nietch, C. T., Kjerfve, B., and Cahoon, D. R. (2002). Responses of coastal wetlands to rising sea level. Ecology 83, 2869-2877. doi: 10.1890/0012-9658(2002)083[2869:ROCWTR]2.0.CO;2

Müller-Navarra, K., Milker, Y., Bunzel, D., Lindhorst, S., Friedrich, J., Arz, H.W., et al. (2019). Evolution of a salt marsh in the southeastern North Sea region - anthropogenic and natural forcing. Estuar. Coast. Shelf Sci. 218, 268-277. doi: 10.1016/j.ecss.2018.12.022

Murray, N. J., Clemens, R. J., Phinn, S. R., Possingham, H. P., and Fuller, R. A. (2014). Tracking the rapid loss of tidal wetlands in the Yellow Sea. Front. Ecol. Environ. 12, 267-272. doi: 10.1890/130260

Ouyang, X., and Lee, S. (2014). Updated estimates of carbon accumulation rates in coastal marsh sediments. Biogeosciences 11, 5057-5071. doi: 10.5194/bg-11-5057-2014

Palmer, M. A., Bernhardt, E. S., Chornesky, E. A., Collins, S. L., Dobson, A. P., Duke, C. S., et al. (2005). Ecological science and sustainability for the 21st century. Front. Eco. Environ. 3, 4-11. doi: 10.1890/15409295(2005)003[0004:ESASFT]2.0.CO;2

Redfield, A. C. (1972). Development of a New England salt marsh. Ecol. Monogr. 42, 201-237. doi: 10.2307/1942263

Rieb, J. T., Chaplin-Kramer, R., Daily, G. C., Armsworth, P. R., Böhning-Gaese, K., Bonn, A., et al. (2017).When, where, and how nature matters for ecosystem services: challenges for the next generation of ecosystem service models. Bioscience 67, 820-833. doi: 10.1093/biosci/bix075

Rizzetto, R., and Tosi, L. (2012). Rapid response of tidal channel networks to sealevel variations (Venice Lagoon, Italy). Glob. Planet. Chang. 92-93, 191-197. doi: 10.1016/j.gloplacha.2012.05.022

Rova, S., Meire, P., Müller, F., Simeoni, M., and Pranovi, F. (2019). A Petri net modelling approach to explore the temporal dynamics of the provision of multiple ecosystem services. Sci. Total Environ. 655, 1047-1061. doi: 10.1016/j.scitotenv.2018.11.184
Santana-Cordero, A. M., Arizab, E., and Romagos, F. (2016). Studying the historical evolution of ecosystem services to inform management policies for developed shorelines. Environ. Sci. Policy 64, 18-29. doi: 10.1016/j.envsci.2016.06.002

Schile, L. M., Callaway, J. C., Morris, J. T., Stralberg, D., Parker, V. T., and Kelly, M., (2014). Modeling tidal marsh distribution with sea level rise: evaluating the role of vegetation, sediment, and upland habitat in marsh resiliency. PLoS ONE 9:e88760. doi: 10.1371/journal.pone.0088760

Torio, D. D., and Chmura, G. L. (2013). Assessing coastal squeeze of tidal wetlands. J. Coast. Conserv. 29, 1049-1061. doi: 10.2112/JCOASTRES-D-12-00162.1

Turner, N., Davidson-Hunt, I., and O'Flaherty, M. (2003). Living on the edge: ecological and cultural edges as sources of diversity for socialecological resilience. Hum. Ecol. 31, 439-461. doi: 10.1023/A:102502 3906459

Walls, S. C. (2018). Coping with constraints: achieving effective conservation with limited resources. Front. Ecol. Evol. 6:24. doi: 10.3389/fevo.2018.00024

Wang, R., Liu, K., Ye, X., and Yan, S. (2018). Association between cerebral microbleeds and depression in the general elderly population: a meta-analysis. Front. Psychiatry. 9:94. doi: 10.3389/fpsyt.2018.00094

Wu, W., Yang, Z., Tian, B., Huang, Y., and Zhang, T. (2018). Impacts of coastal reclamation on wetlands: loss, resilience, and sustainable management. Estuar. Coast. Shelf Sci. 210, 153-161. doi: 10.1016/j.ecss.2018.06.013

Zhao, J., Tuo, Y., Luo, W., He, S., and Chen, Y. (2018). Prognostic and clinicopathological significance of SATB1 in colorectal cancer: a meta-analysis. Front. Physiol. 9:535. doi: 10.3389/fphys.2018.00535

Conflict of Interest Statement: The author declares that the research was conducted in the absence of any commercial or financial relationships that could be construed as a potential conflict of interest.

Copyright (c) 2019 Carrasco. This is an open-access article distributed under the terms of the Creative Commons Attribution License (CC BY). The use, distribution or reproduction in other forums is permitted, provided the original author(s) and the copyright owner(s) are credited and that the original publication in this journal is cited, in accordance with accepted academic practice. No use, distribution or reproduction is permitted which does not comply with these terms. 